\title{
Are risk aversion and impatience related to cognitive ability?
}

Citation for published version (APA):

Dohmen, T. J., Falk, A., Huffman, D., \& Sunde, U. (2009). Are risk aversion and impatience related to cognitive ability? METEOR, Maastricht University School of Business and Economics. METEOR Research Memorandum No. 040 https://doi.org/10.26481/umamet.2009040

Document status and date:

Published: 01/01/2009

DOI:

10.26481/umamet.2009040

Document Version:

Publisher's PDF, also known as Version of record

\section{Please check the document version of this publication:}

- A submitted manuscript is the version of the article upon submission and before peer-review. There can be important differences between the submitted version and the official published version of record.

People interested in the research are advised to contact the author for the final version of the publication, or visit the DOI to the publisher's website.

- The final author version and the galley proof are versions of the publication after peer review.

- The final published version features the final layout of the paper including the volume, issue and page numbers.

Link to publication

\footnotetext{
General rights rights.

- You may freely distribute the URL identifying the publication in the public portal. please follow below link for the End User Agreement:

www.umlib.nl/taverne-license

Take down policy

If you believe that this document breaches copyright please contact us at:

repository@maastrichtuniversity.nl

providing details and we will investigate your claim.
}

Copyright and moral rights for the publications made accessible in the public portal are retained by the authors and/or other copyright owners and it is a condition of accessing publications that users recognise and abide by the legal requirements associated with these

- Users may download and print one copy of any publication from the public portal for the purpose of private study or research.

- You may not further distribute the material or use it for any profit-making activity or commercial gain

If the publication is distributed under the terms of Article $25 \mathrm{fa}$ of the Dutch Copyright Act, indicated by the "Taverne" license above, 


\section{Maastricht University}

Thomas Dohmen, Armin Falk, David Huff man, Uwe Sunde

Are Risk Aversion and I mpatience Related to Cognitive Ability?

RM/09/040

\section{METEOR}

Maastricht University School of Business and Economics

Maastricht Research School of Economics

of Technology and Organization

P.O. Box 616

NL - 6200 MD Maastricht

The Netherlands 


\title{
Are Risk Aversion and Impatience Related to Cognitive Ability?
}

\begin{abstract}
This paper investigates whether risk aversion and impatience are correlated with cognitive ability. We conduct incentive compatible choice experiments measuring risk aversion, and impatience over an annual time horizon, for a representative sample of roughly 1,000 German adults. A measure of cognitive ability is provided by two submodules of one of the most widely used IQ tests. Interviews are conducted in subjects' own homes. We find that lower cognitive ability is associated with greater risk aversion, and more pronounced impatience. These relationships are statistically and economically significant, and robust to controlling for personal characteristics, educational attainment, income, and measures of liquidity constraints. We perform a series of additional robustness checks, which help rule out other possible confounds.
\end{abstract}

Keywords: Risk Preference, Time Preference,

Cognitive Ability, Field Experiment

JEL codes: C93, D01, D80, D90, J24, J62 


\section{Introduction}

Preferences and cognitive ability are fundamental determinants of decision-making in economic models. Their importance is confirmed empirically by studies showing that individual measures of risk aversion and impatience predict a wide range of important economic outcomes (e.g., Luigi Guiso and Monica Paiella, 2005; Catherine Eckel et al., 2005), and by the literature showing that higher cognitive ability is associated with better labor market outcomes (e.g., James J. Heckman et al., 2006). ${ }^{1}$ In economic models and applications, cognitive ability is typically assumed to be independent of both risk aversion and impatience. This assumption, however, has received relatively little attention in the empirical literature.

This paper tests whether risk aversion and impatience are related to cognitive ability. We use a sample of more than 1,000 adults living in Germany, randomly drawn to be representative of the population, which enhances the generalizability and economic relevance of our findings. ${ }^{2}$ In particular, relying on student subjects only would involve limiting the analysis to only a limited part of the distribution of cognitive ability, and would not allow us to investigate the relationship between cognitive ability and risk aversion and ability for a heterogeneous population. Subjects made choices in paid experiments, which provide incentive compatible and controlled measures of risk aversion and impatience. The measure of risk aversion involved choices over real-stakes lotteries, and the measure of impatience involved making tradeoffs between payments available immediately and payments available in one year. Subjects also took two different sub-modules of a widely used IQ test, providing a measure of cognitive ability. A questionnaire collected information on various personal and background characteristics. The questionnaire and experiments were conducted in subjects' own homes.

Our main finding is that risk aversion and impatience both vary systematically with cognitive ability. Individuals with higher cognitive ability are significantly more willing to take risks in the lottery experiments, and are significantly more patient over the

\footnotetext{
${ }^{1}$ For additional evidence on risk aversion see: Robert B. Barsky et al. (1997); Guiso and Paiella, 2008; Thomas Dohmen et al. (2005); Holger Bonin et al. (2007). For evidence on impatience and behavior see: Luigi Ventura (2003); Chris Kirby and Nancy Petry (2004); Lex Borghans and Bart Golsteyn (2005); Eckel et al. (2005). For additional evidence on cognitive ability, see: Richard J. Herrnstein and Charles Murray (1994); Richard Murnane et al. (1995); John Cawley et al. (2001); Samuel Bowles et al., (2001).

${ }^{2}$ For a discussion of this point see also John List (2003), and Steven Levitt and List (2007).
} 
year-long time horizon studied in the intertemporal choice experiment. The correlation between cognitive ability and risk aversion is present for both young and old, and for males and females, although the relationship is somewhat weaker for females and younger individuals. We find that the correlation of both traits with cognitive ability remains strong and significant even after removing variation due to personal characteristics such as gender, age, and height, as well as important economic variables including education, income, and liquidity constraints. We rule out that various aspects of the experiment or cognitive ability tests explain the correlations, including confusion about incentives in the choice experiments, different propensities to engage in arbitrage, differences in test-taking style for people who are more risk averse or more impatient, and the potential role for personality type, or noncognitive skills, to influence performance on the cognitive ability tests.

Our findings complement the previous literature on this topic in psychology, which has focused on young children or student subjects, and has often used hypothetical measures of risk aversion and impatience. ${ }^{3}$ Although evidence is mixed, several studies from psychology show that higher cognitive ability is associated with greater patience (see, e.g., Noah Shamosh and Jeremy Gray, 2008). ${ }^{4}$ There has been less evidence on cognitive ability and risk in psychology. Two recent papers in behavioral economics also provide evidence on this issue. ${ }^{5}$ Dan Benjamin et al. (2005) show that higher standardized test scores (SAT) for Chilean high school students are associated with risk neutrality, as well as greater patience, in small-stakes monetary choices. Frederick (2006), combining students and adults in the U.S., from various studies, finds similar results. ${ }^{6}$ Different from previous studies,, our experiments show for the first time how cognitive ability relates to risk aversion and impatience in a representative sample of adults, as well as for different sub-groups and age ranges within the population, using incentive compatible measures. The fact that the correlations extend into adulthood, and prime years for economic de-

${ }^{3}$ An exception to the focus on children is the study by John Monterosso et al. (2001), on impatience of cocaine addicts, which finds no relationship with cognitive ability.

${ }^{4}$ For other evidence on the relationship between intelligence and the ability to delay gratification from the psychology literature see, e.g., David Funder and Jack Block (1989), Yuichi Shoda et al. (1990), Kirby et al. (2005), Andrew Parker and Baruch Fischoff (2005).

${ }^{5}$ Some studies provide indirect evidence, e.g., showing that aversion to losses is less pronounced among people with more education (e.g., Guiso and Paiella, 2005; Simon Gächter et al., 2006), and that precision in probabilistic thinking relates to portfolio choice (Lee Lillard and Robert Willis, 2001).

${ }^{6}$ Risk measures were hypothetical. One of the impatience measures involved real money. 
cision making, heightens the economic relevance of these relationships and points to the importance of reexamining the assumption of independence from cognitive ability.

Theories from behavioral economics provide reasons to expect that risk aversion and impatience could be related to cognitive ability. Theories of choice bracketing (Amos Tversky and Daniel Kahneman, 1981; Daniel Read et al., 1999) incorporate the tendency for some people to have trouble bracketing choices broadly, i.e., to recognize how individual risky decisions integrate with other assets like lifetime wealth, or conceptualize and integrate future considerations with current goals. Narrow bracketing can make people behave more risk averse if they do not integrate risky decisions with wealth, or more myopic if they have difficulty incorporating considerations about the future. There is empirical evidence that narrow bracketing is reduced when cognitive costs are lowered. ${ }^{7}$ Thus, the tendency for lower cognitive ability to cause narrow bracketing could be one mechanism explaining our findings.

Another theoretical framework emphasizes the interplay between emotions and cognition in decision making, by taking a "two-system" approach. ${ }^{8}$ The emotional system is assumed to have preferences that are risk averse, and myopic, whereas the cognitive system is assumed to be more risk neutral and to take a longer run view in intertemporal problems. Lab experiments have demonstrated in various ways that a reduced influence of emotions, or stronger influence of cognition, tend to mitigate risk aversion and impatience. ${ }^{9}$ Thus, a two-system decision process is another potential mechanism explaining the negative relationship of risk aversion and impatience with cognitive ability.

\footnotetext{
${ }^{7}$ Matthew Rabin and Georg Weizsäcker (2007) show that narrow bracketing in risky choice is reduced when math is worked out for subjects, and Johannes Abeler and Felix Marklein (2007)) find that narrow bracketing in consumption decisions (violations of fungibility of income) is reduced for people with higher math grades.

${ }^{8}$ Examples include Richard H. Thaler and Hersh M. Shefrin (1981); Janet Metcalfe and Walter Mischel (1999); Douglas Bernheim and Antonio Rangel (2004); Jess Benhabib and Alberto Bisin (2005); Drew Fudenberg and David K. Levine (2006).

${ }^{9}$ For example, subjects in a cognitive load treatment, where they are required to keep in mind a seven digit number, are more likely to choose an unhealthy snack over a less enjoyable but healthy option, compared to people who do not have to remember a number (Baba Shiv and Alexander Fedorikhin, 1999). Similarly, Benjamin et al. (2005) find that inducing a cognitive load leads to more impatient and more risk averse decisions. Another body of evidence shows that damage to emotional systems in the brain tend to reduce risk aversion in risky choice, relative to individuals without such damage (Shiv et al., 2005). Similarly, damage to cognitive brain areas is associated with more myopic behavior, without regard for the future consequences (Antonio Damasio, 1994). Brain imaging studies provide complementary evidence, showing that emotional systems in the brain value immediate rewards, and that stronger activation in cognitive systems relative to emotional systems predict being more patient (Samuel McClure et al., 2004).
} 
Although there are theoretical arguments for a causal impact of cognitive ability on risk aversion and impatience, and empirical demonstrations from laboratory experiments, in principle there could also be important feedback effects. Heckman (2006) and Heckman et al. (2006) argue that the relationship between cognitive and non-cognitive skills is complex, such that non-cognitive skills and personality traits could cause people to endogenously create environments during childhood that foster faster cognitive development. Our particular measures of cognitive ability capture something closer to innate ability than, say, the accumulated knowledge measured by an SAT test score. Thus there is less scope for risk aversion or impatience to affect these types of ability through a channel of greater accumulated experience or knowledge. This does not imply, however, that cognitive ability is not malleable. Hence, a conservative interpretation of the relationships we observe is in terms of correlations rather than causality. Indeed, the focus of this paper is not on adding evidence on the issue of causality, which is conceptually difficult in this context, but rather on establishing whether or not there is a robust and sizeable relationship between these traits that extends into adulthood and across the population as a whole.

The correlations of risk aversion and impatience with cognitive ability have important implications for theoretical and empirical research in economics. For example, the fact that drawing an individual from the population and observing cognitive ability (or proxies such as education or income) is informative about the individual's risk aversion and impatience is highly relevant for models of screening and contract design (e.g., in the tradition of Michael Rothschild and Joseph Stiglitz, 1976). It suggests that contracts can be tailored to observable proxies for cognitive ability in order to select individuals on the basis of willingness to take risks or patience, traits that are of crucial interest to employers, or insurance companies, but are difficult to observe.

The findings are also relevant for empirical applications involving cognitive ability. They point to a different interpretation of reduced form models that have been estimated with cognitive abilities, but not risk aversion or impatience, as explanatory variables (e.g., Cawley et al., 2001). ${ }^{10}$ Outcomes such as educational attainment or wages may be related to risk aversion and impatience, and thus part of the impact of cognitive ability may

10 See also: Herrnstein and Murray (1994); Murnane et al. (1995); Derek Neal and William R. Johnson (1996). 
reflect the correlation with these omitted variables. In other words, there is a potentially important omitted variable bias in such reduced form analyses. In structural estimation, on the other hand, it is more common to include cognitive ability as well as risk aversion and impatience parameters, but the typical assumption is that the latter traits are independent of cognitive ability. There are some exceptions, including Heckman et al. (2006), who allow for cognitive ability to affect the discount rate, and vice versa, in a formal model explaining labor market and behavioral outcomes. Our findings provide an empirical basis for the flexible specification adopted by Heckman et al. (2006), and shed light on the specific nature of the relationship between cognitive ability and traits of risk aversion and impatience.

The correlation of cognitive ability with willingness to take risks, and patience, is also relevant for the literature relating the distribution of cognitive ability to inequality in economic outcomes (e.g., Edwin Leuven et al., 2004; Francine Blau and Lawrence Kahn, 2005). If people who have high cognitive ability are more patient, and thus more likely to make investments, and if they earn a risk premium from being less risk averse, this could exacerbate differences in inequality associated with differences in cognitive ability. In other words, the fact that risk aversion and impatience go together with low cognitive ability could lead to a reinforcing effect on economic outcomes.

The rest of the paper is organized as follows. Section 2 describes the measures of cognitive ability and preferences. Section 3 presents our mian empirical results. Section 4 provides robustness checks. Section 5 concludes.

\section{Data Description}

\subsection{Design of the Study}

The data were collected as part of a study run between June 9th and July 4th, 2005. We conducted the study using the same professional surveying company that administers the German Socio-Economic Panel (SOEP), a large panel data set for Germany (for a detailed description of the SOEP see John Haisken-DeNew and Joachim Frick, 2003; Jürgen Schupp and Gerd G. Wagner, 2002; Wagner et al., 2007). Sampling was done according to the same procedure used to generate the SOEP sample, and individuals were visited by interviewers 
in their own homes. ${ }^{11}$ Our sample was constructed so as to be representative of the adult population, age 17 and older, living in Germany. In total our data include interviews with 1,012 participants.

Participants in our study went through a computer assisted personal interview (CAPI) conducted with a laptop computer. The interview consisted of two parts. First, subjects answered a detailed questionnaire. The items in the questionnaire were presented in the standard format used by the SOEP. Topics included demographic characteristics, financial situation, health, and attitudes. The full questionnaire, in German and translated into English, is available upon request. The questionnaire also contained two tests of cognitive ability. At the end of the questionnaire, subjects were invited to participate in the second part of the interview, which consisted of a paid experiment. A random device in the CAPI software determined whether a subject was invited to participate in a lottery experiment designed to measure the extent of risk aversion, or an intertemporal choice experiment designed to elicit impatience over an annual horizon. ${ }^{12}$ Of all 532 subjects who were invited to take part in the discount rate experiment 500 participated, while 452 out of 480 potential participants took part in the lottery choice experiment.

\subsection{Measures of Cognitive Ability}

Each of the two tests of cognitive ability in our questionnaire is similar to a different module of the Wechsler Adult Intelligence Scale (WAIS), one of the most widely-used intelligence tests worldwide (see Uwe Tewes, 1991). ${ }^{13}$ The Wechsler test has 11 modules, 6 verbal and 5 non-verbal. One of our tests, the symbol-digit correspondence test, is similar to a sub-module in the non-verbal section of the WAIS, which asks subjects to match as many numbers and symbols as possible in a given time according to a given correspondence. In particular, the symbol-digit correspondence test presented subjects with nine unfamiliar symbols, each paired with one of the digits 1 through 9 . After brief instructions, subjects were presented with a screen that had this same mapping from numbers to symbols at the

${ }^{11}$ For each of 179 randomly chosen primary sampling units (voting districts), an interviewer was given a randomly chosen starting address. Starting at that specific local address, the interviewer contacted every third household and had to motivate one adult person aged 17 or older to participate. For a detailed discussion of the random walk method of sampling see Steven K. Thompson (2006).

12 Due to budget and time constraints, it was not feasible to do both experiments with each subject.

${ }^{13}$ We used the German version of the test, which is known as the Hamburger-Wechsler Intelligenztest für Erwachsene (HAWIE-R). 
top. A symbol, with a blank box beneath it, was presented in the center of that screen. Subjects had to type the correct corresponding number into the box. Once a number was entered, a new screen with another symbol appeared. Subjects had 90 seconds to find as many correspondences between symbols and numbers as they could, using the correct number for each symbol. Thus, speed and accuracy in applying the given correspondence under time pressure determine how well an individual does on the test. A total of 105 persons refused to participate, and procedural problems arose in some cases, so we have non-missing symbol-correspondence scores for a total of 902 subjects.

Our other test, the word fluency test, is similar to one of the verbal sub-modules of the WAIS, in which subjects are given a timed vocabulary test. The word fluency test asked subjects to verbally list as many animals as they could in 90 seconds. After each naming, the interviewer pressed one of three keys, to indicate a correct animal name, a name repetition, or the statement of a wrong or unclear name, respectively. ${ }^{14}$ Before the test started, subjects were asked whether they wanted to participate, and 87 subjects refused to take part. Some of the participants who had agreed to participate changed their minds just after the experiment began, and stopped. In a few other cases, procedural problems arose, mostly because interviewers made input errors, for example forgetting to press a key after the interviewee had named an animal. In total, we have word fluency scores for 848 individuals.

Both of our tests are related to speed of processing (Frieder Lang et al., 2007). Due to the time limit and mechanical nature of the tests, both capture how quickly individuals can manipulate or recall information. The symbol-digit correspondence test in particular has the form of a classic speed of processing measure. Speed of processing is a feature of cognitive ability that can affect performance on all higher cognitive tasks (Philip Vernon, 1983). It has also been shown to be a primary factor underlying changes in cognitive ability that occur with aging (Tim A. Salthouse, 2000; Ian Deary and Geoff Der, 2005). Although related to speed of processing, performance on the word fluency test is also correlated with other, more experiential or education-related aspects of intelligence, to a

\footnotetext{
${ }^{14}$ Lang et al. (2005) assessed the error-proneness of this procedure in a laboratory experiment in which they tape-recorded the tests and then compared the correct test results with those resulting from interviewers' entries. On average interviewers were slightly off, recording 0.4 fewer correct answers than the true total. Ceteris paribus this recording error makes the word fluency test a more noisy measure than the symboldigit correspondence test, where there is no scope for recording error, due to computerization of the procedure.
} 
greater degree than the symbol-digit correspondence test (Lang et al., 2007).

Our tests were designed to capture the aspects of intelligence measured by these sub-modules, while also being suitable for implementation in the field as part of a CAPI interview, rather than in the usual paper and pencil format of the WAIS. Previously, the symbol-digit correspondence test and word fluency test used in our study have been shown to be strongly correlated with the corresponding modules of the German version of the WAIS, as well as with the remaining modules, and with scores on other prominent intelligence tests (Lang et al., 2005; Lang et al., 2007).

Figure 1 shows the resulting distributions of cognitive ability in our data. The upper graph in the figure is the histogram of correct answers on the symbol-digit correspondence test. Overlaid is a graph of the smoothed density function of the distribution of symboldigit correspondence test scores, estimated using a Gaussian kernel. ${ }^{15}$ A normal density function is also plotted in the graph, with the same mean and variance as the estimated density. The figure shows that the estimated density function for the symbol-digit correspondence test is close to the normal density, or a "bell-shaped curve", consistent with the usual finding from the literature on cognitive ability. The lower graph of the figure shows the histogram of the number of correct recalls in the word fluency test. Graphs of the smoothed density function are estimated in the same way as in the upper graph, and a normal density is included in the same way as well. The estimated density for the word fluency test is also close to normal. ${ }^{16}$ Given that normality is a reasonable assumption, we use standardized versions of the measures in our analysis, such that the measures are normalized to have mean zero and standard deviation of 1 . Standardization facilitates interpretation of our results, as coefficients from regressions can be interpreted directly as showing the change in risk aversion or impatience associated with a one standard deviation increase in cognitive ability.

The correlation between the two cognitive ability measures is 0.412 (Spearman;

\footnotetext{
15 The bandwidth is chosen to minimize the mean integrated squared error if the data were Gaussian.

16 The distributions of cognitive ability scores are also very similar across the sub-samples involved in the lottery and intertemporal choice experiments, respectively. The hypothesis that the distribution of symbol digit correspondence scores is the same for both sub-samples cannot be rejected using a Kolmogorov-Smirnov test $(\mathrm{p}$-value= 0.487$)$. Also, for both sub-samples we cannot reject the hypothesis that the estimated distribution is normal at the five-percent level, using a joint test of skewness and kurtosis. The distributions are also not significantly different across the lottery and intertemporal choice sub-samples for the word fluency measure ( $\mathrm{p}$-value= 0.396). Although the distributions for word fluency look close to normal for both sub-samples, in the case of the word fluency test we reject normality at the five-percent level. Our results are robust if we instead use the non-standardized measures.
} 
$p<0.001)$, consistent with the two tests capturing a similar underlying trait but also capturing distinct aspects of cognitive ability, respectively. As is done with the WAIS sub-modules, most of our analysis uses a single combined measure of cognitive ability, which is constructed by averaging the two standardized measures and then standardizing the resulting average. This way of combining the measures is a standard procedure, as it helps reducing measurement error and achieving a more reliable measure of cognitive ability. Our results remain unchanged if we use non-standardized measures, and results are similar using the two cognitive ability tests separately.

The standardized average ability measure exhibits a hump-shaped age pattern that increases with age until the twenties, when it begins to decline steadily for all later ages. The pattern is similar for the two separate measures, although the peak in the word fluency test scores occurs at later ages than the peak in the symbol-digit correspondence test scores. This hump-shaped pattern is consistent with a large body of evidence on cognitive ability and aging, which finds a similar pattern using both cross sectional and longitudinal data (see David J. Madden, 2001; Deary and Der, 2005). We take this as an additional indication of the validity of our cognitive ability measure.

\subsection{Experimental Measures of Risk Aversion and Impatience}

We used paid experiments to measure willingness to take risks and impatience. As described above, it was randomly determined whether a subject was invited to participate in the lottery experiment or the intertemporal choice experiment. The exact script and instructions used in the experiments are presented in Appendix ?? below, translated from German into English.

For both experiments, the first step in the procedure involved the experimenter presenting subjects with an example choice table. The experimenter explained the types of choices that the subject would make in the table, and how payment would work. In particular, subjects were informed that the experiment would involve multiple choices, one for each row of the table, and that one table row would be randomly selected after all choices had been made, and that the choice in this row would potentially be relevant for their payoff. Subjects also knew that at the end of the experiment a random device would determine whether they were actually paid, with the probability of being paid equal to $1 / 7$. This procedure gives subjects an incentive to choose according to their true preferences in 
each row, and thus is incentive compatible. After explaining the nature of the experiment and the rules for payment, the experimenter asked subjects whether they were willing to participate. Subjects who agreed to participate were given further instructions, and then allowed to ask questions. Once there were no more questions, the experiment began, and subjects were asked to make their actual choices, referring to the choice table.

We elicited willingness to take risks using choices between a paid lottery and different safe payments. Participants made choices in a table with 20 rows. In each row they had to decide whether they preferred a safe option or playing a lottery. In the lottery they could win either 300 Euros or 0 Euros, each with 50 percent probability (at the time, 1 Euro $\sim \$$ US 1.2). In each row the lottery was exactly the same but the safe option increased from row to row. In the first row the safe option was 0 Euros, in the second it was 10 Euros, and so on up to 190 Euros in row 20.

If subjects have monotonic preferences, they prefer the lottery up to a certain level of the safe option, and then switch to preferring the safe option in all subsequent rows of the choice table (see also Charles A. Holt and Susan K. Laury, 2002, who use a similar choice-table procedure). In our procedure, subjects were asked for their choices one row at a time, starting from the top of the table. Once a subject expressed a preference for the safe option instead of the lottery, the experimenter asked if the subject would also prefer all higher values of the safe option as well. If the answer was affirmative, the experimenter filled in the rest of the choices accordingly. Otherwise the subject could continue making choices in the table. In all cases, subjects responded in the affirmative. The switching point in the lottery experiment is informative about a subject's willingness to take risks. Since the expected value of the lottery is 150 Euros, weakly risk averse subjects should prefer safe options that are smaller than or equal to 150 Euros over the lottery. Only risk loving subjects should opt for the lottery when the offered safe option is greater than 150 Euros.

To create an incentive compatible index for how impatient an individual is, we posed subjects with choices between receiving different payments at different times. As in the lottery experiment, subjects were presented with a choice table and asked to make a choice in each row. The decision in the intertemporal choice experiment was always between 100 Euros "today" and a larger amount $Y$ that would be received 12 months in the future. Moving down the table, the early payment was always 100 Euros but the size of the 
delayed payment $Y$ increased in each subsequent row. The value of $Y$ in the first row gave a return of 2.5 percent, assuming semi-annual compounding, and each subsequent value of $Y$ implied an additional 2.5 percentage point increase in the annual rate of return. ${ }^{17}$ Observing the value of $Y$ (or equivalently, the implied annual rate of return) necessary to induce the individual to wait 12 months, we obtain an index of impatience.

Subjects were asked for their decisions one row at a time, starting from the first row. The first time that a subject switched from 100 Euros to the delayed payment, the subject was asked whether he or she also preferred to wait for any larger payment, which all subjects agreed upon. As in the lottery experiment, subjects knew that one row would be randomly selected at the end of the experiment, and that their decision in that row could be relevant for their payoff. Subjects also knew that all payments would be sent by mail following the interview, in the form of a check. Checks for "today" could be cashed immediately, but checks for payments in 12 months would be cashable only in 12 months.

Our focus in this paper is on the relationship between cognitive ability and impatience, rather than estimating the average level of impatience in the population, but our design does address an important challenge that arises when trying to precisely measure the level of impatience. The potential problem is that subjects could be skeptical that the experimenters will deliver on a promise to make a monetary payment available in the future. This could cause them to place a premium on payments that are available immediately at the time of the interview, and thus choose in a way that makes them appear more impatient than they truly are. In our design, however, there is little scope for credibility concerns. Subjects know that even the early payment is not available immediately, but rather is sent by mail shortly after the interview in the form of a check. The timing of the mailing is thus the same as if the subject is due to receive a check that can only be cashed in one year's time. This feature of the design helps make the early and delayed payments equally credible or "incredible", and thus mitigates the problem of overstating the level of impatience. ${ }^{18}$

${ }^{17}$ We chose semi-annual compounding of the annual interest rate because this is a natural compromise between the two types of compounding German subjects are most familiar with: quarterly compounding on typical bank accounts, and annual reports on the rate of return from savings accounts, pension funds, or stock holdings. Using semi-annual compounding also helps avoid prominent round numbers in the choice table, which could potentially influence switching choices.

${ }^{18}$ Furthermore, experiments and payments were administered by the professional surveying agency used for the SOEP, which is highly credible and well known to the public because of its role in conducting election and opinion polls for German public television. Interviewers also left their contact details at the 
The upper graph of Figure 2 shows the histogram of switching values in the lottery experiment, which are equivalent to subjects' certainty equivalents. The main message of the figure is that there is substantial heterogeneity in willingness to take risks. It is also noteworthy that the majority of individuals are risk averse. The modal certainty equivalent is 100 Euros, well below the lottery's expected value of 150 Euros, and the median certainty equivalent is 80 Euros. These values are in line with previous evidence from laboratory experiments and field experiments that measure the degree of risk aversion. ${ }^{19}$ Overall, the majority of subjects (77.8 percent) exhibit risk aversion in the lottery experiment, preferring a certainty equivalent strictly smaller than the expected value of the lottery to playing the lottery. The fraction of risk-seeking subjects is small (9.1 percent). As is typical in choice experiments, there is also some evidence that subjects tend to choose prominent numbers more often (e.g., 50, 100, 150). In the analysis we use estimation techniques that correct for the fact that willingness to take risks is measured in intervals, and thus is leftand right-censored, and we check robustness of our results to using broader intervals that eliminate much of the lumpiness of the distribution around prominent numbers.

The lower graph of Figure 2 shows the histogram of switching values in the intertemporal choice experiment. Again, the main message of the figure is that there is substantial heterogeneity. It is noteworthy that the implied level is similar to that in other recent studies that use behavior in the field to infer impatience. ${ }^{20}$ Note that there is a spike in the

end of the experiment, making it easy for subjects to contact the institute. There were no reports, from any of the interviewers, about subjects expressing concerns regarding credibility of payments. Thus, it is very unlikely that subjects perceived either future or immediate payments in the experiment as being less than fully credible.

19 Previous studies using lottery experiments have often assumed a CRRA utility function, and utility defined over outcomes in the experiment rather than final wealth levels, in order to infer a risk preference parameter (but see Rabin, 2000, for a criticism of this approach). Applying these assumptions to our data for the sake of comparability yields mean and median coefficients of relative risk aversion that fall in the range between 0.43 and 0.48 . This is similar to the range of 0.3 to 0.5 found by Holt and Laury (2002) in laboratory experiments with college students, and is reasonably close to the value 0.67 found by Glenn Harrison et al. (2007) in a field experiment with people in Denmark.

${ }^{20}$ Under certain assumptions it is possible to infer an annual discount rate from switching rows in the experiment, and to compare to annual discount rates estimated in previous studies that make similar assumptions. For example, with locally-linear utility and semi-annual compounding of the annual discount rate, the lower bound for the annual discount rate is given by the formula $100 *(1+\underline{\delta} / 2)^{2}=Z$, where $Z$ is the largest value of the delayed payment such that the individual still prefers 100 Euros today. The upper bound is calculated as $100 *(1+\bar{\delta} / 2)^{2}=Y$, where $Y$ is the value of the delayed payment in the next row of the table, i.e., the smallest delayed payment that makes the individual willing to switch to waiting one year. An individual's true discount rate $\delta$ lies within this interval, $\delta \in[\underline{\delta}, \bar{\delta}]$. The resulting median discount rate falls in the range of 27.5 to 30 percent. Harrison et al. (2002) make similar assumptions, except using quarterly instead of semi-annual compounding, and find an average annual discount rate of 28.1 percent in their field experiment with individuals in Denmark. John T. Warner and Saul Pleeter (2001) provide evidence on annual discount rates for a large number 
figure in the highest category of impatience; this reflects individuals who are so impatient that they prefer the early payment even in the final row of the choice table. There is again some evidence that prominent numbers affect choices: switching is slightly more common in rows where the delayed payment surpasses prominent numbers, for example 110 Euros, or 120 Euros, although this feature of choices appears less pronounced than in the lottery experiment. In the analysis we take steps to correct for left and right censoring of the impatience measure, and check robustness to using intervals that mitigate lumpiness around prominent numbers.

\section{Results}

In the raw data, it is apparent that risk aversion and impatience vary systematically with cognitive ability. The correlation between cognitive ability and risk aversion is -0.233 (Spearman; $p<0.001$ ), and for cognitive ability and impatience the correlation is -0.124 (Spearman; $p<0.011$ ). Figure 3 shows the relationships graphically. Higher cognitive ability is associated with greater willingness to take risks, measured by the certainty equivalent in the switching row for the lottery experiment. Higher levels of cognitive ability are also associated with reduced impatience, as shown by a decreasing rate of return in the switching row in the intertemporal choice experiment.

Table 1 investigates whether these relationships hold regardless of which cognitive ability measure is used. The dependent variable in columns (1) to (3) is the switching row in the lottery experiment. A higher switching row indicates a higher certainty equivalent, and thus a greater willingness to take risks. The three columns show the relationship between willingness to take risks and the symbol digit correspondence, word fluency, and combined cognitive ability measures, respectively. The dependent variable in columns (4) to (6) is the switching row in the intertemporal choice experiment. A higher value indicates that an individual needs a higher rate of return to forgo the immediate payment and wait one year, and thus greater impatience. To account for the fact that the dependent variables are measured in intervals, and thus that all observations are right and left

of individuals in the U.S. military, inferred from very high stakes choices between different voluntary separation options. They find an average annual discount rate ranging from 10 to 19 percent for officers and from 35 to 55 percent for enlisted soldiers. 
censored, the regressions are estimated using interval regression techniques. ${ }^{21}$ Coefficient estimates are marginal effects; robust standard errors are reported in brackets. Unless otherwise noted, all subsequent tables in the paper also report interval regressions, and robust standard errors. In all regressions we use the standardized measures of cognitive ability as explanatory variables.

Columns (1) to (3) show that willingness to take risks is positively correlated with cognitive ability, significant at the one percent level, regardless of the cognitive ability measure used. ${ }^{22}$ Consistent with a reduction in measurement error, the measure with the strongest relationship, and the smallest relative standard error, is the combined measure. Columns (4) to (6) show a similar pattern for impatience. Higher cognitive ability is associated with significantly less impatience, for all three cognitive ability measures, but the relationship is strongest for the combined cognitive ability measure.

The partial correlations shown in Table 1 are also economically significant. A one standard deviation increase in the combined cognitive ability score is associated with a shift of about 1.25 switching rows in the lottery experiment, which corresponds to a 15.3 percent increase in the certainty equivalent for the median subject in our sample. For the intertemporal choice experiment, a one standard deviation increase in the combined cognitive ability measure is associated with switching about 1.5 rows earlier. This corresponds to a 14.6 percent decrease in the rate of return needed to induce the median individual to switch to preferring the delayed payment. ${ }^{23}$

Table 2 explores whether the relationships of risk aversion and impatience to cog-

${ }^{21}$ The procedure maximizes a likelihood function that is a natural generalization of a Tobit, treating each value as a left and right censored observation coming from an interval with known bounds. Error terms are assumed to be normally distributed.

22 Notably, this result does not appear to be driven by a tendency for people with higher cognitive ability to better understand expected values, or use expected value as a choice heuristic. If this were the case, we would expect an effect of cognitive ability mainly by increasing the probability of switching exactly in those rows that correspond to risk neutrality (rows 15 and 16). We do not, however, observe an especially relation between cognitive ability and the tendency to be risk neutral. In fact, only about 3 percent more subjects switch in rows 15 and 16 among the top quartile of the symbol digit correspondence distribution, compared to the bottom quartile. Instead, in the data we observe that higher cognitive ability is associated with a shift of the entire distribution of switching rows in the direction of greater willingness to take risks. We reach a similar conclusion if we estimate probit regressions, where the dependent variable is equal to 1 in the case of risk neutrality. Cognitive ability does not have a significant relation with the probability of being risk neutral ( $p>0.38$; detailed results available upon request). Thus, the results in Table 1 reflect a tendency for people with higher cognitive ability being less risk averse in general.

23 This calculation uses as the denominator the interval midpoint for the rate of return implied by the median switching row. 
nitive ability are stable across different sub-populations, or whether the effect is stronger for certain groups. We consider sub-populations in terms of age and gender. Columns (1) and (2) show that higher cognitive ability is associated with significantly greater willingness to take risks, for people below median age and above median age, respectively. The relationship appears essentially the same, and is not significantly different, between the young and old sub-populations. Columns (3) and (4) show that results are qualitatively similar whether one considers men or women. The size of the correlation between risk aversion and cognitive ability is smaller for women than for men, but this difference is not statistically significant. Columns (5) to (8) show that the relationship between higher cognitive ability and impatience remains negative and of substantial magnitude, whether cutting the sample by median age, or by gender. The relationships are weaker for people below median age, and weaker for women than for men.

In summary, risk aversion and impatience both vary systematically with cognitive ability. Higher cognitive ability is associated with greater willingness to take risks, and greater patience, as measured by the incentivized experiments. Qualitatively similar relationships are found using alternative measures of cognitive ability, and using different sub-samples of our representative sample.

\section{Robustness}

In this section we explore the robustness of the relationships of risk aversion and impatience with cognitive ability. We first investigate whether the (partial) correlations of risk aversion and impatience with cognitive ability remain significant and large, after controlling for variation due to other characteristics, and then perform additional robustness checks.

Columns (1) and (5) of Table 3 show regressions for risk aversion and impatience, respectively, controlling for gender, height, and age. We include these characteristics because all have been found by previous studies to be related to traits like risk aversion or impatience, as well as cognitive ability (e.g., Dohmen et al., 2005; Anne Case and Christina Paxon, 2008). The quadratic in age controls for a potentially non-linear relationship of willingness to take risks, and patience, with age. ${ }^{24}$ Column (1) shows that there remains

${ }^{24}$ In the raw data both risk aversion and impatience follow a hump-shaped profile over the age range This 
a strong and significant positive relationship between cognitive ability and willingness to take risks, controlling for these characteristics. Column (5) shows that the relationship between cognitive ability and impatience is still similarly negative and significant after adding these controls.

In Columns (2) and (6) of Table 3, we add controls for other important characteristics, including the number of children in the household and education. We control for education using dummy variables for different educational degrees. This is a more meaningful measure of educational attainment for Germany than years of schooling, because of the structure of the German educational system (see David Card, 1999, p. 1806). ${ }^{25}$ In Columns (3) and (7) we additionally control for (log) household income and potential liquidity constraints. The income variable is current household monthly income, net of taxes and benefits (for more details see the table notes). The dummy variable for liquidity constraints is based on a question in our questionnaire, which asked the following: "If you suddenly encountered an unforeseen situation, and had to pay an expense of 1,000 Euros within the next two weeks, would it be possible for you to make that payment?" We control for number of children with separate dummy variables for one, two, and three or more children.

Both risk aversion and impatience are significantly correlated with cognitive ability, controlling for these additional characteristics. Columns (2) and (3) show that the relationship between willingness to take risks and cognitive ability is somewhat smaller after the inclusion of children and education, as well as income variables (including or excluding controls for number of children has essentially no impact on the coefficient on cognitive ability). Nevertheless, the coefficient on cognitive ability remains economically significant, and statistically significant at the ten percent level, despite the decrease in sample size due to missing values on income. In Columns (6) and (7), we see that there is only a small reduction in the (absolute) value of the coefficient relating impatience and cogni-

pattern motivated our specification. Results turn out to be essentially identical, however, with only a linear term in age. The observation that patience is decreasing for much of the age range starting beyond the mid fifties might also be interpreted as reflecting the impact of a shorter time horizon due to the approaching end of life. Interestingly when we use a survey question that asks individuals for their subjective life expectancy, we find no relationship between life expectancy and impatience (and also willingness to take risks), casting doubt on this interpretation.

${ }^{25}$ In teenage years, German students select into different types of high schools, some focusing on vocational training, others intended to prepare students for college. Thus, an equal number of years of education can imply very different education attainment depending on the type of degree. 
tive ability, and the coefficient remains significant at the five percent level. Thus, there remain robust correlations of risk aversion and impatience with cognitive ability, after controlling for important characteristics. ${ }^{26}$ Interestingly, higher income is associated with significantly greater willingness to take risks, as is being unconstrained in terms of borrowing possibilities. Higher income is also significantly negatively correlated with impatience, while liquidity constraints are not. Neither educational degree or number of children are significantly related to willingness to take risks, or impatience, with the exception that individuals with three or more children in the household are significantly more impatient than individuals with no children. ${ }^{27}$

An interesting possibility pointed out by Carmit Segal (2006) is that performance on cognitive tests could partly measure aspects of a subject's personality, rather than cognitive ability. If our measures of cognitive ability in fact proxy for personality type, then our findings could be interpreted as revealing a correlation between fundamentally important traits in economics (risk aversion and impatience) and personality traits. If this were the case, it would be an interesting finding in its own right, albeit with different implications. ${ }^{28}$ In our questionnaire we included standard measures of the "Big Five" personality traits, so we can test whether cognitive ability is related to risk aversion and impatience, controlling for conscientiousness and other dimensions of personality.

Columns (4) and (8) of Table 3 report regressions that include controls for personal characteristics, education, income, and number of children, but also add gender-interacted controls for what psychologists have agreed are five key dimensions of personality: conscientiousness, extroversion, agreeableness, openness, and neuroticism. ${ }^{29}$ We find that none

${ }^{26}$ Given that the focus is on the correlation between cognitive ability and risk aversion or impatience rather than causality, adding "behaviorally endogenous" controls, like income, does not invalidate the analysis, since by construction residuals are orthogonal to the controls in this type of regression context. The coefficients on cognitive ability capture the direct relations with risk aversion or impatience, respectively. The point of the exercise is to exclude indirect sources of correlation, for example, due to a tendency for cognitive ability to be associated with high income, which is in turn associated (not necessarily causally) with a greater willingness to take risks.

27 These results are robust to including a quadratic term for cognitive ability. The quadratic term is jointly significant with the linear term, and negative (positive) for risk aversion (impatience). With the addition of controls, however, the quadratic term is no longer significant while the linear term remains large and significant.

28 See Heckman et al. (2006) for a discussion of the importance of investigating the link between economic preferences and non-cognitive skills or personality traits.

29 The Big-Five questionnaire measures personality traits by asking subjects how much they agree with different statements about themselves. We use a fifteen item version of the questionnaire where each trait is assessed based on level of agreement with three statements. The subject indicates the level of 
of the personality characteristics is significantly related to risk aversion or impatience, controlling for the other characteristics. Controlling for personality type leaves the results for cognitive ability almost unaffected. The main conclusion to be drawn from Columns (4) and (8) is that the coefficients on cognitive ability are still statistically significant and quantitatively large, even when including measures of personality type in addition to all other controls.

The results in Table 3 are robust to using different estimation techniques like OLS instead of interval regressions. ${ }^{30}$ The results are also likely to be robust to unobserved heterogeneity, which would have to be strongly correlated with cognitive skills and the dependent variables, and, at the same time, only have a weak correlation with all the other controls that are already included in the model, in order to explain the correlation of interest. We also explored the robustness of the results to collapsing the preference measures into broader intervals around prominent numbers. Using these smoothed measures, rather than intervals containing single rows, makes sense if some of the people who switch at prominent numbers in fact prefer to switch a row earlier or a row later, but are "attracted" by the prominent number and switch at that point by mistake. The results of a significant relation between cognitive ability and risk aversion or patience are qualitatively similar to those presented in Table $3 .{ }^{31}$ Finally, we also took a different approach to dealing with censoring of the dependent variable from the intertemporal choice experiment, and used a Cox mixed proportional hazards model. We estimated the impact of cognitive ability on the hazard of switching in the choice table, from the immediate to the delayed payment in the intertemporal choice experiment. We found similar results in this case: the coefficient estimates show that higher cognitive ability significantly decreases the

agreement on a seven-point scale, and response are added across each set of three statements to achieve a score for that personality trait. Statements are presented in random order. Gender interactions account for the possibility of systematic differences between women and men in the way they respond to questions about personality traits and in their relation with experimental outcomes, see, e.g., Segal (2008).

30 The coefficient estimates ( $\mathrm{p}$-values) for cognitive ability in the regressions of willingness to take risks are 0.781 (p-value $<0.011$ ) for the specification controlling for gender, age and height, and 0.564 (p-value $<0.081)$ in the full specification with controls for income, liquidity constraints, education, number of children, and personality types. The corresponding coefficients in the impatience regressions are -0.942 (p-value $<0.012)$ and $-0-810$ (p-value $<0.051)$.

${ }^{31}$ When collapsing 4 switching rows at a time into one bin in the lottery experiments, combining responses in the intervals $[1,4],[5,8],[9,12],[13,16],[17,20]$, the coefficient estimates of our cognitive ability measure are 0.250 (p-value $<0.01$ ) for the specification controlling for gender, age and height, and 0.187 (p-value $<0.05)$ for the full specification with all controls. In the time preference experiment, the corresponding estimates are -0.314 ( $p$-value $<0.01$ ) and -0.258 ( $p$-value $<0.05$ ), respectively. 
hazard of switching in the intertemporal choice experiment, which corresponds to greater patience. $^{32}$

A potential confound would arise if risk aversion and impatience are not related to true cognitive ability, but instead influence the type of test-taking strategy that subjects adopt, in a way that leads to lower measured cognitive ability. For instance, suppose that risk averse individuals take more time to provide answers in the tests of cognitive ability because this preference partly reflects a desire to avoid losses, or mistakes. This would lead to a lower error rate on the test, but potentially also to a lower score because subjects answer fewer questions within the time limit. We test the hypothesis that risk aversion has an impact on the error rates in the tests. It is less plausible that impatience would affect the way that an individual approaches the tests of cognitive ability. The tests take 90 seconds, regardless of effort, so there is no incentive for an impatient individual to rush through the cognitive ability exercises. Nevertheless, we also check whether impatient individuals have higher error rates on the tests of cognitive ability.

In OLS regressions, we regress the error rates in the tests of cognitive ability on willingness to take risks and impatience, with and without controls for personal characteristics. ${ }^{33}$ The error rate is defined as the number of incorrect answers divided by the total number of answers given by an individual. For both tests of cognitive ability, there is no significant impact of risk aversion or impatience on error rates, in any specification. ${ }^{34}$ Thus, there is little indication that the baseline results reflect an impact of risk aversion or impatience on test-taking strategy.

Another potential confound that is specific to the intertemporal choice experiment arises if people with high cognitive ability are more likely to engage in arbitrage behavior. In particular, it could be that some highly impatient subjects adopt a sophisticated strategy of arbitrage. They might make patient choices in the experiment in order to take advantage of the above-market rates of return, and then borrow outside of the experiment at market interest rates to finance their desire for immediate consumption. If use of this strategy is more likely for individuals with high cognitive ability, then intelli-

\footnotetext{
${ }^{32}$ Coefficient estimates are 0.168 (p-value $<0.01$ ) and 0.138 (p-value $<0.05$ ) for the specification only with controls for gender age and height, and for the specification with all controls, respectively.

33 Results are available upon request.

${ }^{34}$ Point estimates are essentially zero, and none are close to being statistically significant. These results are available upon request.
} 
gent people could be just as impatient as those with low ability, but simply appear more patient in the experiment because they have figured out a less expensive way to finance immediate consumption. To identify individuals who engaged in arbitrage, we asked at the end of the experiment whether a subject had thought about market interest rates at all during the experiment. Of all participants, roughly 37 percent say that they thought about an interest rate. This suggests that most subjects are not engaging in arbitrage at all. Interestingly, however, thinking about market rates of return is positively correlated with cognitive ability. ${ }^{35}$ When including a dummy variable equal to 1 if an individual thought about market interest rates and 0 otherwise as additional control in our baseline specifications for impatience, thinking about interest rates implies a large and statistically significant decrease in the discount rate observed in the experiment. This is consistent with those who think about interest rates engaging in arbitrage. The more important finding for our purposes, however, is that higher cognitive ability is still associated with a significantly lower degree of impatience. ${ }^{36}$ To account for the possibility that individuals of higher cognitive ability, who are more patient, are also more likely to think about the market interest rate, which would imply a smaller absolute change in switching rows due to thinking about interest rate, we also included an interaction term. However, it turns out that the interaction between cognitive ability and thinking about the interest rate is not significantly different from zero. ${ }^{37}$

Because we rely on choice experiments to measure willingness to take risks and impatience, another potential concern is that low cognitive ability could be associated with confusion about incentives faced in the experiments, in a way that happens to be observationally equivalent to greater risk aversion, or greater impatience. Confusion is unlikely,

35 The Spearman rank correlation between the standardized average cognitive ability measure and the dummy whether an individual thought about the market interest rate is 0.07 ( $\mathrm{p}$-value $<0.14$ ).

36 The coefficient estimates ( $\mathrm{p}$-values) for the standardized average cognitive ability measure and for the dummy indicating that a subject thought about the interest rate are -0.962 (p-value $<0.072$ ) and 5.433 ( $\mathrm{p}$-value $<0.01$ ), respectively, in the full specification including controls for log household income, liquidity constraints, education and number of children.

37 The coefficient (p-value) for the interaction term in the specification with controls for gender, age, age squared, height and a dummy for thinking about the interest rate is -1.20 (p-value $<0.193$ ). In this specification, the marginal effect of the standardized cognitive ability score, evaluated at the sample mean of the dummy for thinking about the interest rate $(0.36)$ is -1.18 ( $\mathrm{p}$-value $<0.015)$. The interaction coefficient in a full specification including controls for log household income, liquidity constraints, education and number of children is -1.39 ( $\mathrm{p}$-value $<0.15$ ), and the corresponding marginal effect of the average cognitive ability score at the sample mean of thought about the interest rate $(0.37)$ is -0.89 ( $\mathrm{p}$-value $<0.099$ ). As in the case without interactions, thinking about the interest rate has a significantly negative effect on impatience in the specifications that include an interaction term. 
given that the experiments are relatively simple. Also, it is not clear why confusion should be systematic in a way that would appear as greater risk aversion or impatience. ${ }^{38}$ In the case of willingness to take risks, however, we are able to address this potential confound directly. Our data include a very simple survey question about risk attitudes that is immune to problems of confusion about incentives, filling out tables, etc.. The question asks an individual to rate his or her own "willingness to take risks, in general" on a scale from 0 to 10 , where 0 is "completely unwilling" and 10 is "completely willing." In previous research, this particular question has been shown to be a good predictor of a wide variety of risky behaviors, including holding stocks, being self-employed, smoking, migrating, and participating in sports (see, for example, Dohmen et al., 2005; Bonin et al., 2007; Jaeger et al., 2009).

Table 4 presents regressions where the dependent variable is the response to the survey question about willingness to take risks. Column (1) shows that individuals with higher cognitive ability rate themselves as significantly more willing to take risks. ${ }^{39}$ Columns (2) to (4) use the same specifications as in Columns (1), with all of our other controls from Table 3, and find a similarly significant relationship between cognitive ability and willingness to take risks. Thus, our results are unlikely to be explained by confusion about incentives in the choice experiments.

\section{Conclusion}

The goal of this paper was to investigate whether the key traits of risk aversion and impatience are systematically related to cognitive ability, and to do so for the first time using the combination of incentive compatible measures, and a representative sample of adults. The main finding is that people with lower cognitive ability are significantly more risk averse, and significantly more impatient. This is true controlling for personal character-

${ }^{38}$ In the case of the intertemporal choice experiment, for example, confused individuals could well appear more patient. For instance, suppose that subjects ignore the time delay, and think that one of the two columns in the table is randomly selected, rather than one row. Given that payments are always larger in the second column, which gives the delayed payments, confused subjects would tend to choose delayed payments and thus appear more patient.

${ }^{39}$ We also find similar results running regressions for different sub-samples. The relationship between self-rated willingness to take risks and cognitive ability is present for sub-samples involving individuals below median age $(p<0.001)$, above median age $(p<0.001)$, and for both males $(p<0.001)$ and females $(p<0.001)$. 
istics, educational attainment, income, and liquidity constraints. The relationship also survives a series of additional robustness checks.

These relationships have important implications for theoretical and empirical research in economics. For example, it is important to take into account that cognitive ability conveys information about the crucial traits of risk aversion and impatience, for understanding contract design and screening strategies. For empirical applications, it may be appropriate to allow for a positive correlation between cognitive ability and risk preference, and a negative correlation between cognitive ability and discount rates, when estimating structural models or interpreting reduced form estimates. For example, consider a regression of schooling choice on cognitive ability: the coefficient on cognitive ability will partly reflect the correlation with omitted risk aversion and impatience, which are both relevant for investments in human capital. Given the importance of risk aversion and impatience for many other economic decisions, this is likely to be true more generally for regressions of economic decisions or outcomes on cognitive ability. For example, the relationship between cognitive ability and inequality is reinforced, if low and high cognitive ability are associated with unfavorable and favorable patterns of risky and intertemporal choice, respectively.

In terms of policy implications, the results raise important questions for interventions designed to improve cognitive ability, which typically focus on young children due to evidence that early childhood environment has a strong impact on cognitive skills (see, e.g., Heckman, 2006; Eric Knudsen et al., 2006). If higher cognitive ability leads to greater patience and greater willingness to take risks, this is an important, additional effect of such interventions, with far-reaching implications for a child's future economic outcomes. Alternatively, if patience and willingness to take risk tend to foster the accumulation of greater cognitive ability, interventions focused on influencing these non-cognitive skills could provide a different approach to improving cognitive ability and economic outcomes. 


\section{References}

Abeler, Johannes and Felix Marklein, "Fungibility, Labeling, and Consumption," 2007. IZA Working Paper.

Barsky, Robert B., Thomas F. Juster, Miles S. Kimball, and Matthew D. Shapiro, "Preference Parameters and Individual Heterogeneity: An Experimental Approach in the Health and Retirement Study," Quarterly Journal of Economics, May 1997, $112(2), 537-579$.

Benhabib, Jess and Alberto Bisin, "Modelling Internal Commitment Mechanisms and Self-Control: A Neuroeconomics Approach to Consumption-Saving Decisions," Games and Economic Behaviour, 2005, 52 (2), 460-492.

Benjamin, Daniel, Sebastian Brown, and Jesse Shapiro, "Who is "Behavioral"?," 2005. Harvard University Working Paper.

Bernheim, B. Douglas and Antonio Rangel, "Addiction and Cue-Triggered Decision Processes," American Economic Review, 2004, 94 (5), 1558-1590.

Blau, Francine and Lawrence Kahn, "Do Cognitive Test Scores Explain Higher U.S. Wage Inequality?," Review of Economics and Statistics, 2005, 87 (1), 184-193.

Bonin, Holger, Thomas Dohmen, Armin Falk, David Huffman, and Uwe Sunde, "Cross-sectional Earnings Risk and Occupational Sorting: The Role of Risk Attitudes," 2007, 14 (6), 926-937. Labour Economics.

Borghans, Lex and Bart Golsteyn, "Imagination, Time Discounting and Human Capital Investment Decisions," 2005. Maastricht University Working Paper.

Bowles, Sammuel, Herbert Gintis, and Melissa Osborne, "The Determinants of Earnings: A Behavioral Approach," Journal of Economic Literature, 2001, 39 (4), $1137-1176$.

Card, David, "The Causal Effect of Education on Earnings," in O. Ashenfelter and D. Card, eds., Handbook of Labor Economics, Vol. 3A Elsevier Science North-Holland 1999.

Case, Anne and Christina Paxson, "Stature and Status: Height, Ability, and Labor Market Outcomes," Journal of Political Economy, 2008, 116 (3), 499-532.

Cawley, John, James Heckman, and Edward Vytlacil, "Three Observations on Wages and Measured Cognitive Ability," Labour Economics, 2001, 8, 419-442.

Damasio, Antonio, Descarte's Error: Emotion, Reason, and the Human Brain, New York: G. P. Putnam, 1994.

Deary, Ian and Geoff Der, "Reaction Time, Age, and Cognitive Ability: Longitudinal Findings from Age 16 to 63 Years in Representative Population Samples," Aging, Neuropsychology, and Cognition, 2005, 12, 187-215. 
Dohmen, Thomas, Armin Falk, David Huffman, Uwe Sunde, Jürgen Schupp, and Gert G. Wagner, "Individual Risk Attitudes: New Evidence from a Large, Representative, Experimentally-Validated Survey," 2005. IZA Discussion Paper No. 1730 .

Eckel, Catherine, Cathleen Johnson, and Claude Montmarquette, "Saving Decisions of the Working Poor: Short- and Long-Term Horizons," in J. Carpenter, G. Harrison, and J. List, eds., Research in Experimental Economics Volume 10: Field Experiments in Economics, Elsevier Science Oxford 2005, pp. 219-260.

Fudenberg, Drew and David K. Levine, "A Dual Self Model of Impulse Control," American Economic Review, 2006, 96 (5), 1449-1476.

Funder, David and Jack Block, "The Role of Ego-Control, Ego-Resiliency, and IQ in Delay of Gratification in Adolescence," Personality and Social Psychology, 1989, 57 (6), 1041-1050.

Gächter, Simon, Andreas Herrmann, and Eric Johnson, "Exploring the Nature of Loss Aversion," CeDEx Discussion Paper, 2006, 2006-02.

Guiso, L. and M. Paiella, "The Role of Risk Aversion in Predicting Individual Behavior," 2005. Bank of Italy Economic Working Paper No. 546.

__ and _ _ "Risk-Aversion, Wealth, and Background Risk," Journal of the European Economic Association, 2008, 6 (6), 1109-1150.

Haisken-DeNew, John P. and Joachim Frick, Desktop Companion to the German Socio-Economic Panel Study (SOEP), Berlin: DIW, 2003.

Harrison, Glenn W., Morten Igel Lau, and Elisabet E. Rutström, "Estimating Risk Attitudes in Denmark: A Field Experiment," Scandanavian Journal of Economics, 2007, 109 (2), 341-368.

, and Melonie B. Williams, "Estimating Individual Discount Rates in Denmark: A Field Experiment," American Economic Review, 2002, 92 (5), 1606-1617.

Heckman, James, "Skill Formation and the Economics of Investing in Disadvantaged Children," Science, June 2006, 312 (5782), 1900-1902.

, Jora Stixrud, and Sergio Urzua, "The Effects of Cognitive and Noncognitive Abilities on Labor Market Outcomes and Social Behavior," Journal of Labor Economics, 2006, 24 (3), 411-482.

Herrnstein, Richard J. and Charles Murray, The Bell Curve, New York: The Free Press, 1994.

Holt, Charles A. and Susan K. Laury, "Risk Aversion and Incentive Effects," American Economic Review, 2002, 92 (5), 1644-1655.

Jaeger, David, Holger Bonin, Thomas Dohmen, Armin Falk, David Huffman, and Uwe Sunde, "Direct Evidence on Risk Attitudes and Migration," Review of Economics and Statistics, forthcoming, 2009. 
Kirby, Chris and Nancy Petry, "Heroine and Cocaine Abusers Have Higher Discount Rates for Delayed Rewards than Alcoholics or Non-Drug-Using Controls," Addiction, 2004, 99, 461-471.

, Gordon Winston, and Mariana Santiesteban, "Impatience and Grades: Delay-Discount Rates Correlate Negatively with College GPA," Learning and Individual Differences, 2005, 15 (3), 213-222.

Knudsen, Eric, James Heckman, Judy Cameron, and Jack Shonkoff, "Economic, Neurobiological, and Behavioral Perspectives on Building Americas Future Workforce," Proceedings of the National Academy of Sciences, July 2006, 103 (27), 10155-10162.

Lang, Frieder, D. Weiss, A. Stocker, and B. von Rosenbladt, "Assessing Cognitive Capacities in Computer-Assisted Survey Research: Two Ultra-Short Tests of Intellectual Ability in the German Socio-Economic Panel (SOEP)," Schmollers Jahrbuch, 2007, 127 (1).

Lang, Frieder R., Dorothee Hahne, Stefanie Gymbel, Stefan Schröpper, and Katharina Lutsch, "Erfassung des kognitiven Leistungspotenzials und der "Big Five" mit Computer-Assited-Personal-Interviewing (CAPI): Zur Reliabilität und Validität zweier ultrakurzer Tests und des BFI-S," 2005. DIW Research Notes 9/2005, DIW Berlin.

Leuven, Edwin, Hessel Oosterbeek, and Hans van Ophem, "Explaining international differences in male wage inequality by differences in demand and supply of skill," Economic Journal, 2004, 144, 478-498.

Levitt, Steven and John List, "What do laboratory experiments tell us about the real world?," Journal of Economic Perspectives, 2007, 21 (2), 153-174.

Lillard, Lee and Robert Willis, "Cognition and Wealth: The Importance of Probabilistic Thinking," 2001. University of Michigan Working Paper.

List, John, "Does Market Experience Eliminate Market Anomalies?," Quarterly Journal of Economics, 2003, 118 (1), 41-71.

Madden, David J., "Speed and Timing of Behavioral Processes," in J. Birren and K. Schaie, eds., Handbook of the Psychology of Aging, Academic Press San Diego 2001, pp. 288-312.

McClure, Samuel, David Laibson, George Loewenstein, and Jonathan Cohen, "Separate Neural Systems Value Immediate and Delayed Monetary Rewards," Science, October 2004, 306, 503-507.

Metcalfe, Janet and Walter Mischel, "A hot/cool-system analysis of delay of gratification: Dynamics of willpower," Psychological Review, 1999, 106 (1), 3-19.

Monterosso, John, Ronald Ehrman, Kimberly Napier, Charles O'Brien, and Anna Childress, "Three Decisions-Making Tasks in Cocaine-Dependent Patients: Do They Measure the Same Construct?," Addiction, 2001, 96 (12), 1825-1837. 
Murnane, Richard J. John B. Willett, and Frank Levy, "The Growing Importance of Cognitive Skills in Wage Determination," Review of Economics and Statistics, 1995, 77, 251-266.

Neal, Derek A. and William R. Johnson, "The Role of Pre-Market Factors in BlackWhite Wage Differences," Journal of Political Economy, October 1996, 104 (5), 869895.

Parker, Andrew and Baruch Fischoff, "Decision-Making Competence: External Validation through an Individual-Differences Approach," Journal of Behavioral Decision Making, 2005, 18 (1), 1-27.

Rabin, Matthew, "Risk Aversion and Expected Utility Theory: A Calibration Theorem," Econometrica, Sep 2000, 68 (5), 1281-1292.

and Georg Weizsäcker, "Narrow Bracketing and Dominated Choices," 2007. Seminar Presentation.

Read, Daniel, George Loewenstein, and Matthew Rabin, "Choice Bracketing," Journal of Risk and Uncertainty, 1999, 19 (1-3), 171-197.

Rothschild, Michael and Joseph Stiglitz, "Equilibrium in Competitive Insurance Markets: An Essay on the Economics of Imperfect Information," Quarterly Journal of Economics, nov 1976, 90 (4), 629-649.

Salthouse, Tim A., "Aging and measures of processing speed," Biological Psychology, $2000,54,35-54$.

Schupp, Juergen and Gert G. Wagner, "Maintenance of and Innovation in LongTerm Panel Studies The Case of the German Socio-Economic Panel (GSOEP)," Allgemeines Statistisches Archiv, 2002, 86 (2), 163-175.

Segal, Carmit, "Motivation, Test Scores, and Economic Success," Universitat Pompeu Fabra, Department of Economics and Business Working Paper, 2008, 1124.

Shamosh, Noah A. and Jeremy R. Gray, "Delay discounting and intelligence: a meta-analysis," Intelligence, 2008, 36 (4), 289-305.

Shiv, Baba and Alexander Fedorikhin, "Heart and Mind in Conflict: The Interplay of Affect and Cognition in Consumer Decision Making," Journal of Consumer Research, 1999, 26 (3), 278-292.

, George Loewenstein, Antoine Bechara, Hanna Damasio, and Antonio Damasio, "Investment Behavior and the Dark Side of Emotion," Psychological Science, June 2005, 16, 435-439.

Shoda, Yuichi, Walter Mischel, and Philip Peake, "Predicting Adolescent Cognitive and Self-Regulatory Competencies from Pre-School Delay of Gratification: Identifying Diagnostic Conditions," Developmental Psychology, 1990, 26 (6), 978-986.

Tewes, Uwe, Hamburger-Wechsler Intelligenztest für Erwachsene, Bern, Switzerland: Huber, 1991. 
Thaler, Richard H. and Hersh M. Shefrin, "An Economic Theory of Self-Control," Journal of Political Economy, 1981, 89 (2), 392-406.

Thompson, Steven K., "Targeted Random Walk Designs," Survey Methodology, 2006, $32(1), 11-24$.

Tversky, Amos and Daniel Kahneman, "The Framing of Decisions and the Psychology of Choice," Science, 1981, 211, 453-458.

Ventura, Luigi, "Direct Measures of Time Preference," The Economic and Social Review, 2003, 34 (3), 293-310.

Vernon, Philip, "Speed of Information Processing and General Intelligence," Intelligence, 1983, 7 (1), 53-70.

Wagner, Gert G., Joachim R. Frick, and Jürgen Schupp, "The German SocioEconomic Panel Study (SOEP) Scope, Evolution and Enhancements," Schmollers Jahrbuch, 2007, 127 (1), 139-169.

Warner, John T. and Saul Pleeter, "The Personal Discount Rate: Evidence from Military Downsizing Programs," American Economic Review, March 2001, 91 (1), $33-53$. 
Figures 
Figure 1: Distribution of Scores in the Cognitive Skills Tests
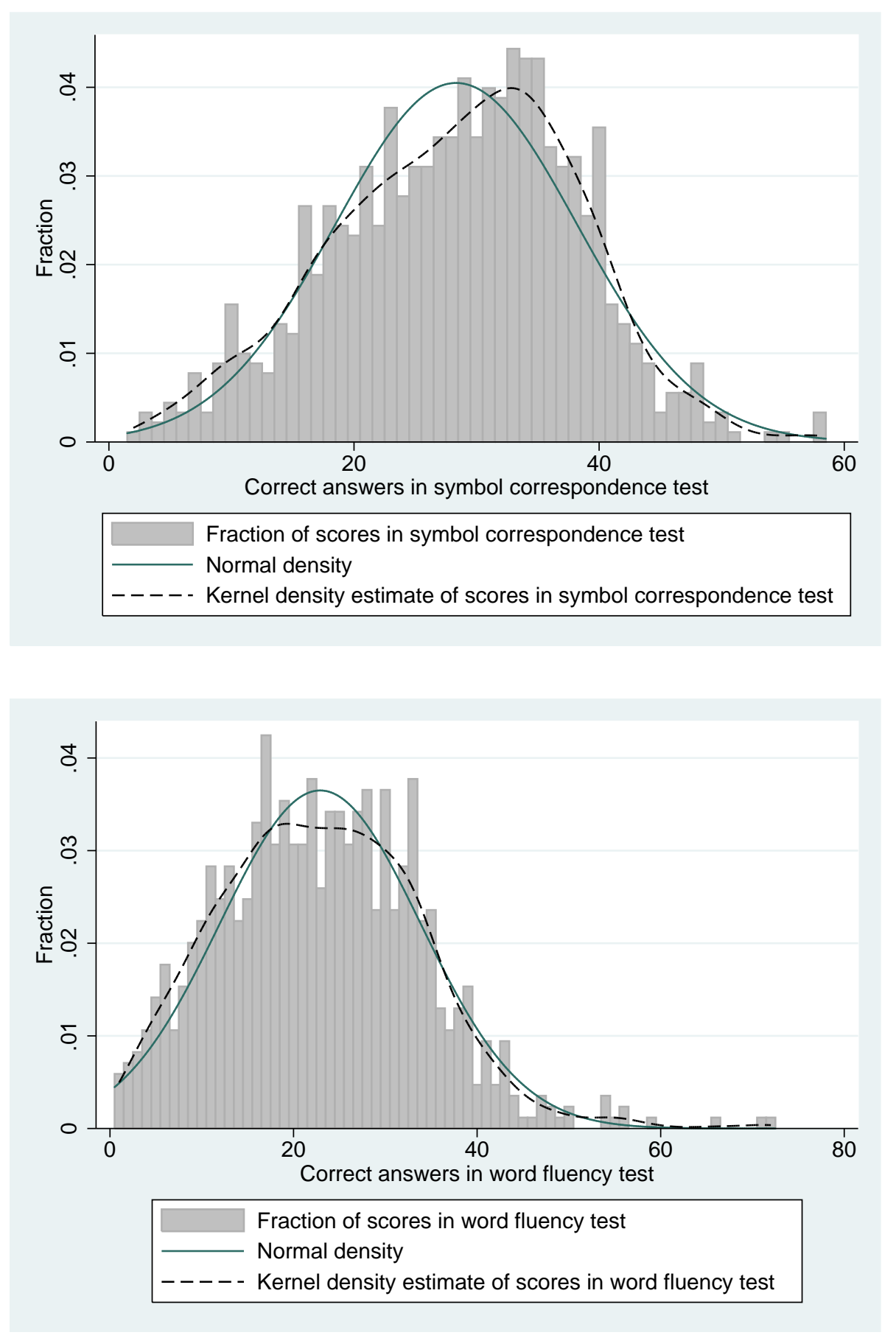

Note: The upper panel shows the histogram of correct responses in the symbol digit correspondence test. Overlaid is the smoothed density function of the distribution of scores, estimated using a Gaussian kernel. The bandwidth is chosen to minimize the mean integrated squared error if the data were Gaussian. A normal density is also plotted in the graph, with the same mean and variance as the estimated function. The lower panel of the figure shows the histogram of the number of correct recalls in the word fluency test. Graphs of the smoothed density function, and normal density, are estimated in the same way as in the upper panel. 
Figure 2: Distributions of Choices in the Lottery and Intertemporal Choice Experiments
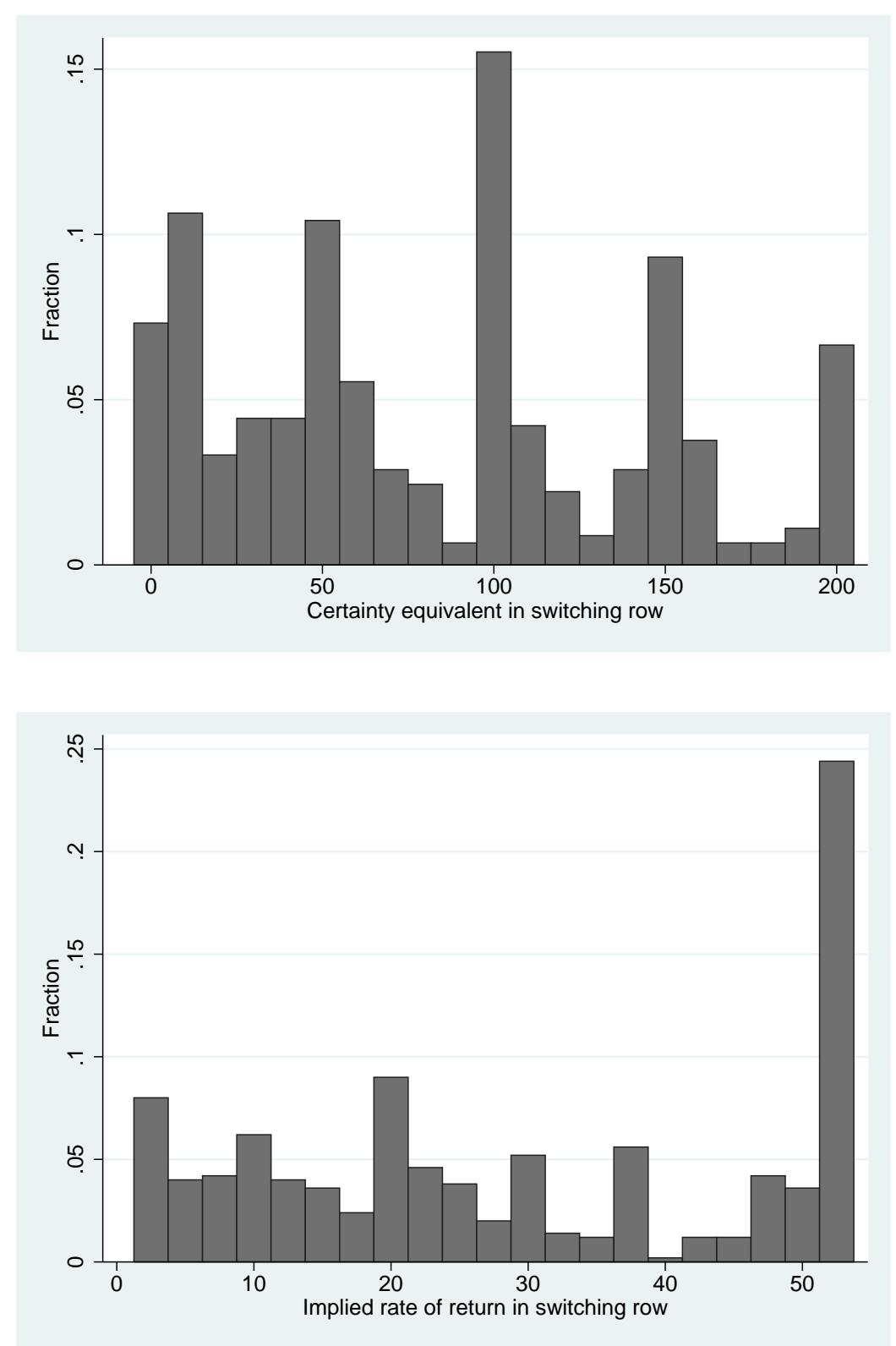

Notes: The upper panel of the figure shows the distribution of choices in the lottery experiment. Values are the safe payment necessary to induce a subject to forgo the chance to play the lottery involving 300 Euros or 0 Euros with equal probability. The lower panel shows the distribution of decisions in the intertemporal choice experiment. Values indicate the rate of return, paid one year in the future, necessary to induce a subject to forgo the chance to receive 100 Euros immediately. 
Figure 3: Willingness to Take Risks, and Impatience, by Cognitive Ability Percentile

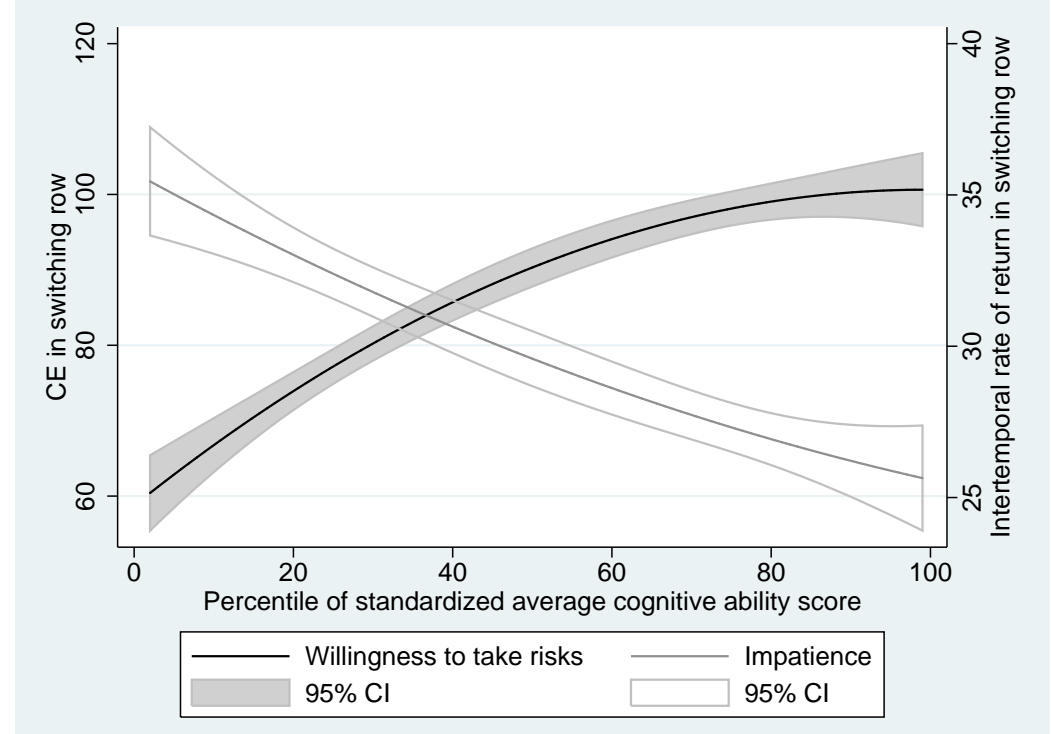

Notes: Polynomial fitted regressions. The combined cognitive ability measure is the standardized average score on the standardized symbol digit correspondence and word fluency tests. Willingness to take risks is measured by switching row in the lottery experiment. Patience is measured by switching row in the intertemporal choice experiment. All traits are standardized to have mean zero and variance of 1. 
Tables 


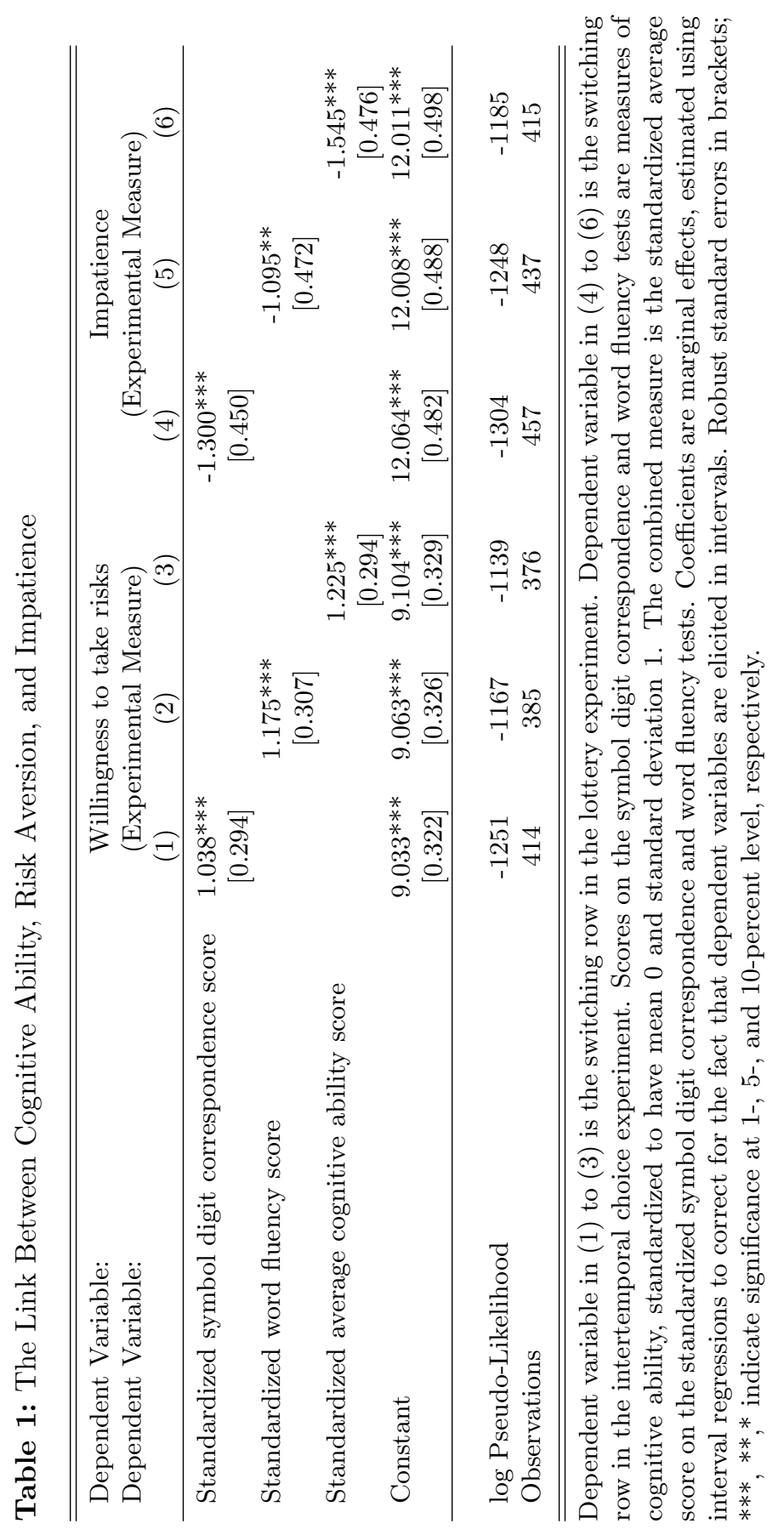




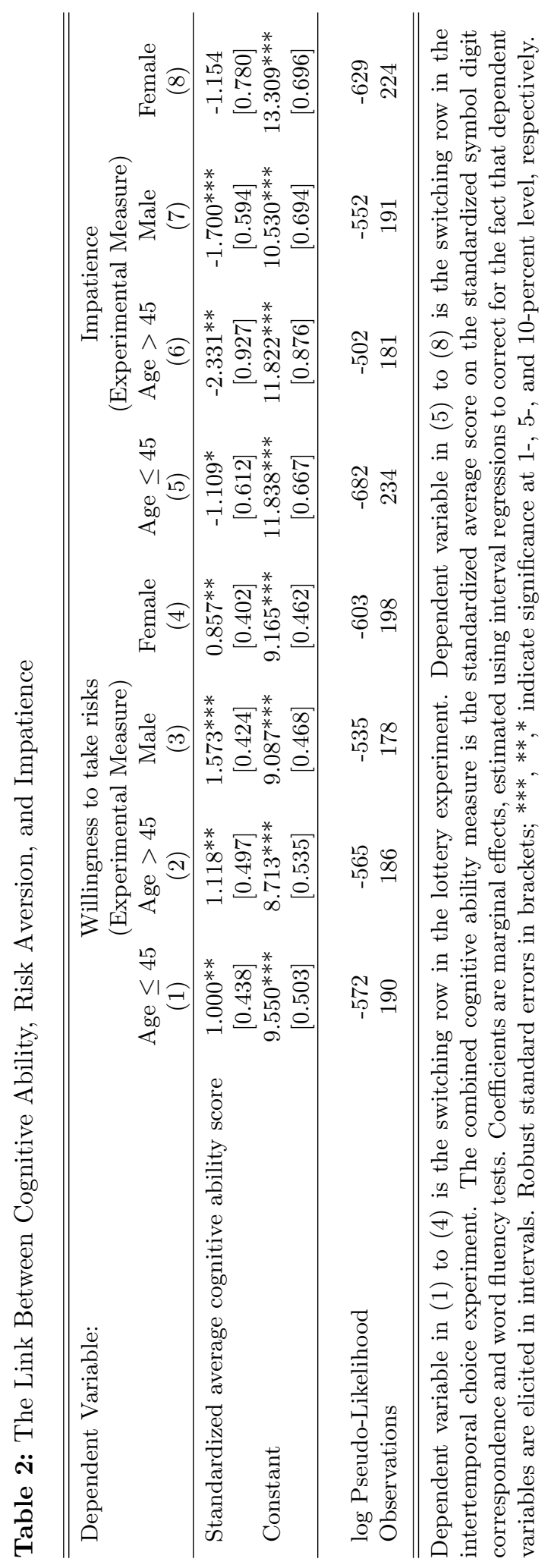




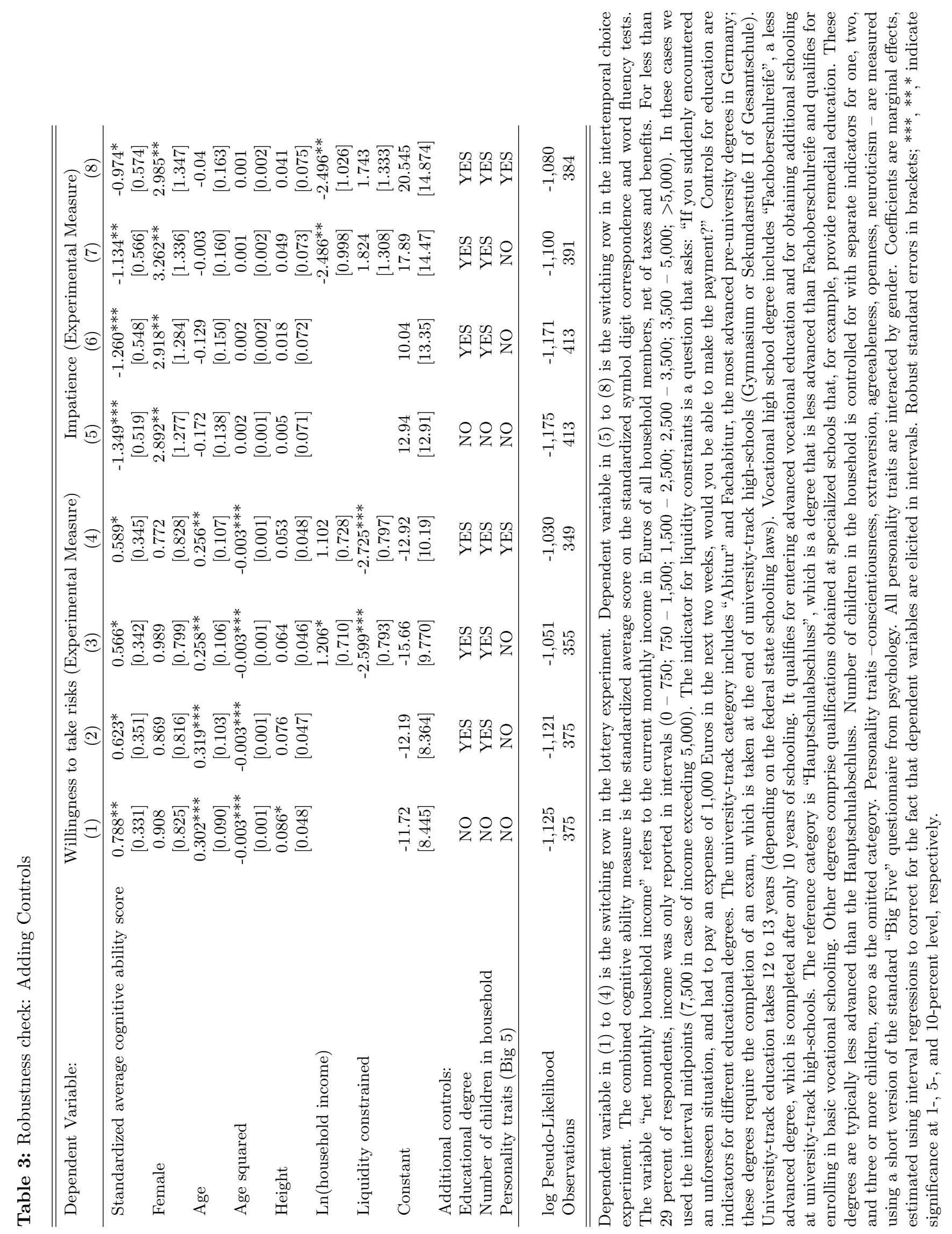


Table 4: Robustness Check: Survey Measure of Risk Aversion

\begin{tabular}{|c|c|c|c|c|}
\hline \multirow[t]{2}{*}{ Dependent Variable: } & \multicolumn{4}{|c|}{ Willingness to take risks (Survey Measure) } \\
\hline & $(1)$ & $(2)$ & $(3)$ & $(4)$ \\
\hline \multirow[t]{2}{*}{ Standardized average cognitive ability score } & $0.560 * * *$ & $0.418^{* * *}$ & $0.315^{* * *}$ & $0.226^{* *}$ \\
\hline & {$[0.088]$} & [0.099] & {$[0.106]$} & {$[0.102]$} \\
\hline \multirow[t]{2}{*}{ Female } & & -0.327 & -0.333 & $-0.389^{*}$ \\
\hline & & {$[0.225]$} & {$[0.236]$} & {$[0.223]$} \\
\hline \multirow[t]{2}{*}{ Age } & & $-0.052^{* *}$ & $-0.061^{* *}$ & $-0.074^{* *}$ \\
\hline & & {$[0.025]$} & {$[0.031]$} & {$[0.030]$} \\
\hline \multirow[t]{2}{*}{ Age squared } & & 0.000 & 0.001 & $0.001^{* *}$ \\
\hline & & {$[0.000]$} & {$[0.000]$} & {$[0.000]$} \\
\hline \multirow[t]{2}{*}{ Height } & & 0.014 & 0.012 & 0.013 \\
\hline & & {$[0.013]$} & {$[0.013]$} & {$[0.013]$} \\
\hline \multirow[t]{2}{*}{ Ln(household income) } & & & 0.294 & 0.259 \\
\hline & & & {$[0.190]$} & {$[0.186]$} \\
\hline \multirow[t]{2}{*}{ Liquidity constrained } & & & -0.028 & -0.055 \\
\hline & & & {$[0.249]$} & {$[0.246]$} \\
\hline \multirow[t]{2}{*}{ Constant } & $4.479^{* * *}$ & 3.816 & 1.438 & 2.104 \\
\hline & {$[0.088]$} & {$[2.359]$} & {$[2.887]$} & {$[2.804]$} \\
\hline \multicolumn{5}{|l|}{ Additional controls: } \\
\hline Educational degree & $\mathrm{NO}$ & $\mathrm{NO}$ & YES & YES \\
\hline Number of children in household & NO & NO & YES & YES \\
\hline Personality traits (Big 5) & $\mathrm{NO}$ & $\mathrm{NO}$ & $\mathrm{NO}$ & YES \\
\hline log Pseudo-Likelihood & $-1,833$ & $-1,814$ & $-1,704$ & $-1,645$ \\
\hline Observations & 813 & 810 & 763 & 749 \\
\hline
\end{tabular}

The dependent variable in columns (1) to (4) is a survey measure of willingness to take risks. Respondents rate their willingness to "take risks, in general" on a scale from 0 to 10 , where 0 indicates "not at all willing" and 10 indicates "very willing". The combined cognitive ability measure is the standardized average score on the standardized symbol digit correspondence and word fluency tests. The variable "net monthly household income" refers to the current monthly income in Euros of all household members, net of taxes and benefits. For less than 29 percent of respondents, income was only reported in intervals $(0-750 ; 750-1,500 ; 1,500-2,500$; $2,500-3,500 ; 3,500-5,000 ;>5,000)$. In these cases we used the interval midpoints $(7,500$ in case of income exceeding 5,000$)$. The indicator for liquidity constraints is a question that asks: "If you suddenly encountered an unforeseen situation, and had to pay an expense of 1,000 Euros in the next two weeks, would you be able to make the payment?" Controls for education are indicators for different educational degrees. The university-track category includes "Abitur" and Fachabitur, the most advanced pre-university degrees in Germany; these degrees require the completion of an exam, which is taken at the end of university-track high-schools (Gymnasium or Sekundarstufe II of Gesamtschule). University-track education takes 12 to 13 years (depending on the federal state schooling laws). Vocational high school degree includes "Fachoberschulreife", a less advanced degree, which is completed after only 10 years of schooling. It qualifies for entering advanced vocational education and for obtaining additional schooling at universitytrack high-schools. The reference category is "Hauptschulabschluss", which is a degree that is less advanced than Fachoberschulreife and qualifies for enrolling in basic vocational schooling. Other degrees comprise qualifications obtained at specialized schools that, for example, provide remedial education. These degrees are typically less advanced than the Hauptschulabschluss. Number of children in the household is controlled for with separate indicators for one, two, and three or more children, zero as the omitted category. Personality traits -conscientiousness, extraversion, agreeableness, openness, neuroticism - are measured using a short version of the standard "Big Five" questionnaire from psychology. All personality traits are interacted by gender. Coefficients are marginal effects, estimated using interval regressions to correct for the fact that dependent variables are elicited in intervals. Robust standard errors in brackets; ***, **,* indicate significance at 1-, 5-, and 10-percent level, respectively. 